\title{
Association of blood pressure in late adolescence with subsequent mortality: cohort study of Swedish male conscripts
}

\author{
Johan Sundström, associate professor, ${ }^{1}$ Martin Neovius, associate professor, ${ }^{2}$ Per Tynelius, statistician, ${ }^{3}$ Finn \\ Rasmussen, professor $^{3}$
}

${ }^{1}$ Department of Medical Sciences and Uppsala Clinical Research

Center, Uppsala University, SE75185 Uppsala, Sweden

${ }^{2}$ Clinical Epidemiology Unit, Department of Medicine Karolinska Institutet, SE-17177 Stockholm, Sweden

${ }^{3}$ Child and Adolescent Public Health Epidemiology Unit,

Department of Public Health Sciences, Karolinska Institutet

Correspondence to: I Sundström johan.sundstrom@medsci.uu.se

Cite this as: BMJ 2011;342:d643 doi:10.1136/bmi.d643

\section{ABSTRACT}

Objective To investigate the nature and magnitude of relations of systolic and diastolic blood pressures in late adolescence to mortality.

Design Nationwide cohort study.

Setting General community in Sweden.

Participants Swedish men ( $n=1207141)$ who had military conscription examinations between 1969 and 1995 at a mean age of 18.4 years, followed up for a median of 24 (range 0-37) years.

Main outcome measures Total mortality, cardiovascular mortality, and non-cardiovascular mortality.

Results During follow-up, 28934 (2.4\%) men died. The relation of systolic blood pressure to total mortality was $U$ shaped, with the lowest risk at a systolic blood pressure of about $130 \mathrm{~mm} \mathrm{Hg}$. This pattern was driven by the relation to non-cardiovascular mortality, whereas the relation to cardiovascular mortality was monotonically increasing (higher risk with higher blood pressure). The relation of diastolic blood pressure to mortality risk was monotonically increasing and stronger than that of systolic blood pressure, in terms of both relative risk and population attributable fraction (deaths that could be avoided if blood pressure was in the optimal range). Relations to cardiovascular and non-cardiovascular mortality were similar, with an apparent risk threshold at a diastolic blood pressure of about $90 \mathrm{~mm} \mathrm{Hg}$, below which diastolic blood pressure and mortality were unrelated, and above which risk increased steeply with higher diastolic blood pressures.

Conclusions In adolescent men, the relation of diastolic blood pressure to mortality was more consistent than that of systolic blood pressure. Considering current efforts for earlier detection and prevention of risk, these observations emphasise the risk associated with high diastolic blood pressure in young adulthood.

\section{INTRODUCTION}

High blood pressure is the most important risk factor for premature death, ${ }^{1}$ and its global burden is increasing. ${ }^{2}$ Systolic blood pressure increases with age, whereas diastolic blood pressure reaches its maximum in middle age and decreases thereafter. ${ }^{3}$ Systolic blood pressure is a stronger predictor of death than is diastolic blood pressure in middle aged and older populations. ${ }^{4}$ Because of a notion that the general public and physicians may be confused by two blood pressure values, a focus on systolic blood pressure has recently been suggested in those age groups. ${ }^{5}$

In younger people, the predominant blood pressure abnormality is a high diastolic blood pressure. The most common form of hypertension in young adults is thus isolated diastolic hypertension, ${ }^{67}$ when classifications based mainly on middle aged and older populations are used. Whether blood pressure limits recommended for middle aged and older people are applicable in adolescents is unknown. Because mortality is low in adolescents, no previous population based study has been large enough to investigate relations of systolic and diastolic blood pressures to mortality in this age group. ${ }^{8}$ Relations of systolic and diastolic blood pressures to risk of cardiovascular events have been reported in selected samples of college students and young industrial workers with questionable generalisability, ${ }^{9-11}$ and in the sample studied here. ${ }^{12}$ Because cardiovascular diseases contribute to only a small minority of all deaths in young adults, the importance of both systolic and diastolic blood pressures for all cause mortality as well as cause specific mortality should be investigated in this age group. Prevention of premature deaths has a higher priority than postponement of deaths in the older population, ${ }^{13}$ and prevention should be started early in life. ${ }^{8}$ Observations of rising blood pressures in adolescents, as a result of the obesity epidemic, are a further motivation for unravelling the relations of blood pressures to mortality in young people. ${ }^{14}$

We hypothesised that both systolic and diastolic blood pressures in young adults contribute to risk of death and that diastolic blood pressure may be more important than systolic blood pressure. We further hypothesised that the relations of systolic and diastolic blood pressures to mortality in young people may be non-linear and that relations to cardiovascular and non-cardiovascular mortality may differ. We investigated the shape and magnitude of these relations by 
Table 1|Baseline characteristics. Values are percentages (numbers) unless stated otherwise

\begin{tabular}{|c|c|c|c|c|c|c|c|c|c|c|c|}
\hline \multirow[b]{2}{*}{ Variable } & \multirow[b]{2}{*}{$\begin{array}{l}\text { Total } \\
\text { sample }\end{array}$} & \multicolumn{5}{|c|}{ Fifths of systolic blood pressure } & \multicolumn{5}{|c|}{ Fifths of diastolic blood pressure } \\
\hline & & $\begin{array}{l}1 \mathrm{st}(80 \mathrm{to} \\
119 \mathrm{~mm} \mathrm{Hg})\end{array}$ & $\begin{array}{l}\text { 2nd (120 to } \\
125 \mathrm{~mm} \mathrm{Hg})\end{array}$ & $\begin{array}{l}3 \text { rd (126 to } \\
130 \mathrm{~mm} \mathrm{Hg})\end{array}$ & $\begin{array}{l}\text { 4th (131 to } \\
138 \mathrm{~mm} \mathrm{Hg})\end{array}$ & $\begin{array}{l}5 \text { th }(139 \text { to } \\
184 \mathrm{~mm} \mathrm{Hg})\end{array}$ & $\begin{array}{l}1 \mathrm{st}(30 \mathrm{to} \\
59 \mathrm{~mm} \mathrm{Hg})\end{array}$ & $\begin{array}{l}\text { 2nd (60 to } \\
65 \mathrm{~mm} \mathrm{Hg})\end{array}$ & $\begin{array}{l}3 \mathrm{rd}(66 \text { to } \\
70 \mathrm{~mm} \mathrm{Hg})\end{array}$ & $\begin{array}{l}\text { 4th (71 to } \\
76 \mathrm{~mm} \mathrm{Hg})\end{array}$ & $\begin{array}{c}5 \text { th }(77 \text { to } \\
120 \mathrm{~mm} \mathrm{Hg})\end{array}$ \\
\hline No of men & 1207141 & 221732 & 270830 & 242337 & 247466 & 224776 & 239379 & 254539 & 288977 & 196920 & 227326 \\
\hline $\begin{array}{l}\text { Mean }(\mathrm{SD}) \text { systolic blood } \\
\text { pressure }(\mathrm{mm} \mathrm{Hg})\end{array}$ & $128(11)$ & $113(4)$ & $122(2)$ & $129(2)$ & $135(2)$ & $144(6)$ & $127(11)$ & $127(11)$ & $128(11)$ & $129(10)$ & $132(10)$ \\
\hline $\begin{array}{l}\text { Mean (SD) diastolic blood } \\
\text { pressure }(\mathrm{mm} \mathrm{Hg})\end{array}$ & $68(10)$ & $65(9)$ & $67(9)$ & $68(10)$ & $68(10)$ & $70(11)$ & $53(4)$ & $62(2)$ & $69(2)$ & $74(2)$ & $82(4)$ \\
\hline $\begin{array}{l}\text { Mean }(\mathrm{SD}) \text { mean arterial } \\
\text { pressure }(\mathrm{mm} \mathrm{Hg})\end{array}$ & $88(8)$ & $81(6)$ & $85(6)$ & $88(7)$ & $90(7)$ & $95(8)$ & $78(4)$ & $83(4)$ & $88(4)$ & $92(4)$ & $99(5)$ \\
\hline $\begin{array}{l}\text { Mean (SD) pulse pressure } \\
(\mathrm{mm} \mathrm{Hg})\end{array}$ & $61(14)$ & $48(9)$ & $55(9)$ & $61(10)$ & $67(10)$ & $75(12)$ & $74(12)$ & $65(11)$ & $59(11)$ & $55(10)$ & $51(10)$ \\
\hline Mean (SD) age (years) & $18.4(0.7)$ & $18.4(0.7)$ & $18.4(0.7)$ & $18.4(0.7)$ & $18.4(0.7)$ & $18.4(0.7)$ & $18.2(0.6)$ & $18.3(0.7)$ & $18.4(0.7)$ & $18.4(0.7)$ & $18.5(0.7)$ \\
\hline $\begin{array}{l}\text { Mean (SD) body mass index } \\
\left(\mathrm{kg} / \mathrm{m}^{2}\right)\end{array}$ & $21.7(2.8)$ & $21.0(2.4)$ & $21.3(2.6)$ & $21.7(2.8)$ & $22.0(2.9)$ & $22.3(3.2)$ & $21.6(2.7)$ & $21.5(2.7)$ & $21.6(2.8)$ & $21.7(2.8)$ & $22.0(3.2)$ \\
\hline \multicolumn{12}{|l|}{ Socioeconomic group: } \\
\hline $\begin{array}{l}\text { Non-manual workers at } \\
\text { higher level }\end{array}$ & $\begin{array}{c}8.4(101 \\
055)\end{array}$ & $8.4(18578)$ & $8.0(21745)$ & $8.2(19967)$ & $8.8(21645)$ & 8.5 (19 120) & 8.7 (20 831) & $8.5(21521)$ & $8.4(24260)$ & $8.1(15945)$ & $8.1(18498)$ \\
\hline $\begin{array}{l}\text { Non-manual workers at } \\
\text { intermediate level }\end{array}$ & $\begin{array}{c}19.9 \\
(240248)\end{array}$ & $\begin{array}{c}20.0 \\
(44385)\end{array}$ & $\begin{array}{c}19.8 \\
(53536)\end{array}$ & $\begin{array}{c}19.8 \\
(48044)\end{array}$ & $\begin{array}{c}20.2 \\
(49917)\end{array}$ & $\begin{array}{c}19.7 \\
(44366)\end{array}$ & $\begin{array}{c}20.4 \\
(48703)\end{array}$ & $\begin{array}{c}20.3 \\
(51550)\end{array}$ & $\begin{array}{c}20.0 \\
(57921)\end{array}$ & $\begin{array}{c}19.5 \\
(38326)\end{array}$ & $19.2(43748)$ \\
\hline $\begin{array}{l}\text { Non-manual workers at } \\
\text { lower level }\end{array}$ & $\begin{array}{c}12.5 \\
(150285)\end{array}$ & $\begin{array}{c}12.7 \\
(28089)\end{array}$ & $\begin{array}{c}12.4 \\
(33560)\end{array}$ & $\begin{array}{c}12.5 \\
(30313)\end{array}$ & $\begin{array}{c}12.5 \\
(31021)\end{array}$ & $\begin{array}{c}12.1 \\
(27302)\end{array}$ & $\begin{array}{c}12.7 \\
(30458)\end{array}$ & $\begin{array}{c}12.5 \\
(31682)\end{array}$ & $\begin{array}{c}12.6 \\
(36346)\end{array}$ & $\begin{array}{c}12.2 \\
(24109)\end{array}$ & $12.2(27690)$ \\
\hline Farmers & $5.2(62283)$ & $4.8(10576)$ & $5.3(14322)$ & $5.0(12230)$ & 4.9 (12 089) & $5.8(13066)$ & $4.9(11614)$ & $5.2(13131)$ & $5.1(14791)$ & $5.3(10330)$ & $5.5(12417)$ \\
\hline Skilled workers & $\begin{array}{c}22.2 \\
(267485)\end{array}$ & $\begin{array}{c}22.0 \\
(48801)\end{array}$ & $\begin{array}{c}22.3 \\
(60313)\end{array}$ & $\begin{array}{c}22.2 \\
(53795)\end{array}$ & $\begin{array}{c}22.1 \\
(54602)\end{array}$ & $\begin{array}{c}22.2 \\
(49974)\end{array}$ & $\begin{array}{c}22.3 \\
(53339)\end{array}$ & $\begin{array}{c}22.1 \\
(56203)\end{array}$ & $\begin{array}{c}22.1 \\
(63787)\end{array}$ & $\begin{array}{c}22.3 \\
(43918)\end{array}$ & $22.1(50238)$ \\
\hline Unskilled workers & $\begin{array}{l}23.7(286 \\
398)\end{array}$ & $\begin{array}{c}23.4(51 \\
826)\end{array}$ & $\begin{array}{c}24.2(65 \\
534)\end{array}$ & $\begin{array}{c}23.9(57 \\
841)\end{array}$ & $\begin{array}{c}23.3(57 \\
536)\end{array}$ & $\begin{array}{c}23.9(53 \\
661)\end{array}$ & $\begin{array}{c}21.9(52 \\
517)\end{array}$ & $\begin{array}{c}23.4(59 \\
516)\end{array}$ & $\begin{array}{c}23.7(68 \\
377)\end{array}$ & $\begin{array}{c}24.8(48 \\
741)\end{array}$ & $25.2(57247)$ \\
\hline Others, not classified & $8.2(99387)$ & $8.8(19477)$ & $8.1(21820)$ & $8.3(20147)$ & $8.4(20656)$ & 7.7 (17 287) & $9.2(21917)$ & $8.2(20936)$ & 8.1 (23 495) & $7.9(15551)$ & $7.7(17488)$ \\
\hline \multicolumn{12}{|l|}{$\begin{array}{l}\text { Mean (SD) muscular strength } \\
\text { (Newton): }\end{array}$} \\
\hline Hand grip & $616(98)$ & $603(97)$ & $611(97)$ & 617 (98) & $622(98)$ & 627 (99) & $614(96)$ & $614(98)$ & $615(98)$ & $617(98)$ & $620(100)$ \\
\hline Leg extension & $568(118)$ & $551(115)$ & $560(116)$ & $569(117)$ & 577 (118) & $583(120)$ & $573(118)$ & 567 (118) & $567(117)$ & $565(117)$ & 569 (118) \\
\hline Arm flexion & $387(85)$ & $375(82)$ & $382(83)$ & $388(84)$ & $393(85)$ & $398(86)$ & $389(84)$ & $386(85)$ & $385(84)$ & $386(84)$ & $390(86)$ \\
\hline
\end{tabular}

All means and proportions differed between fifths of both systolic and diastolic blood pressure (all P<0.001).

using a nationwide military conscription cohort of 1.2 million young men.

\section{METHODS}

Study sample

Military conscription was mandatory by law for all male Swedish citizens at the time of the baseline of this study. We used data from the Swedish Military Conscription Registry for 1207329 men born between 1 April 1949 and 1 December 1976 who had conscription tests between 15 September 1969 and 20 December 1995 and had data on all key variables. The specifics of the data from this registry have been outlined in detail before. ${ }^{15}$ Only 2-3\% of all Swedish men were exempted from conscription at this time, in most cases because of severe handicaps or chronic disease. A total amount of non-coverage in the registry of around $17 \%$ is mainly explained by accidental loss of data from 1978, 1984, and 1985 owing to changes in data management at the Conscription Authority. Because the statistical models used may be sensitive to extreme values, we excluded 176 extreme blood pressure outliers $(>(75$ th centile $+3 \times$ interquartile range $)$ and $<(25$ th centile $-3 \times$ interquartile range $))$ and further excluded 12 men with a recorded pulse pressure less than 10 mm Hg. We eventually included 1207141 men with systolic blood pressures of 80 to $184 \mathrm{~mm}$ $\mathrm{Hg}$ and diastolic blood pressures of 30 to $120 \mathrm{~mm} \mathrm{Hg}$.

\section{Baseline examinations}

Blood pressures were measured according to a written protocol. Systolic and diastolic blood pressures were measured after five to 10 minutes of rest in the supine position, with an appropriately sized cuff at heart level. In Sweden, this procedure has been viewed as the gold standard in clinical settings for many decades and is still the most prevalent. This approach to blood pressure measurement in the study might thus mirror standard practice in primary care clinics. Blood pressures in different postures differ by only a few $\mathrm{mm} \mathrm{Hg}$. A single blood pressure measurement was made if systolic blood pressure was $145 \mathrm{~mm} \mathrm{Hg}$ or less and diastolic blood pressure was between 50 and $85 \mathrm{~mm} \mathrm{Hg}$. If measurements were outside these limits, blood pressure was measured a second time and the result of the second measurement was entered in the register and used in the analyses. Blood pressures were to be rounded to the nearest even number, but some rounding to the nearest 5 or $10 \mathrm{~mm} \mathrm{Hg}$ also occurred. Pulse pressure was calculated as systolic minus diastolic blood pressure. Mean arterial pressure was calculated as diastolic pressure plus pulse pressure divided by three. 
Table 2 | Incidence of mortality. Values are percentages (numbers) unless stated otherwise

\begin{tabular}{|c|c|c|c|c|c|c|c|c|c|c|c|}
\hline \multirow[b]{2}{*}{ Variable } & \multirow[b]{2}{*}{$\begin{array}{l}\text { Total } \\
\text { sample }\end{array}$} & \multicolumn{5}{|c|}{ Fifths of systolic blood pressure } & \multicolumn{5}{|c|}{ Fifths of diastolic blood pressure } \\
\hline & & $\begin{array}{l}1 \mathrm{st}(80 \mathrm{to} \\
119 \mathrm{~mm} \mathrm{Hg})\end{array}$ & $\begin{array}{l}\text { 2nd (120 to } \\
125 \mathrm{~mm} \mathrm{Hg})\end{array}$ & $\begin{array}{l}3 \mathrm{rd}(126 \mathrm{to} \\
130 \mathrm{~mm} \mathrm{Hg})\end{array}$ & $\begin{array}{l}\text { 4th }(131 \text { to } \\
138 \mathrm{~mm} \mathrm{Hg})\end{array}$ & $\begin{array}{l}5 \text { th }(139 \text { to } \\
184 \mathrm{~mm} \mathrm{Hg})\end{array}$ & $\begin{array}{l}1 \mathrm{st}(30 \mathrm{to} \\
59 \mathrm{~mm} \mathrm{Hg})\end{array}$ & $\begin{array}{l}\text { 2nd ( } 60 \text { to } \\
65 \mathrm{~mm} \mathrm{Hg})\end{array}$ & $\begin{array}{l}3 \mathrm{rd}(66 \mathrm{to} \\
70 \mathrm{~mm} \mathrm{Hg})\end{array}$ & $\begin{array}{l}\text { 4th (71 to } \\
76 \mathrm{~mm} \mathrm{Hg})\end{array}$ & $\begin{array}{l}5 \text { th }(77 \text { to } \\
120 \mathrm{~mm} \mathrm{Hg})\end{array}$ \\
\hline No of men & 1207141 & 221732 & 270830 & 242337 & 247466 & 224776 & 239379 & 254539 & 288977 & 196920 & 227326 \\
\hline No of deaths & 28934 & 5560 & 6946 & 5705 & 5277 & 5446 & 3943 & 5715 & 6998 & 5234 & 7044 \\
\hline Person years at risk & 28998870 & 5362383 & 6744815 & 5791456 & 5730368 & 5369848 & 5086070 & 6046532 & 7061373 & 4927477 & 5877418 \\
\hline $\begin{array}{l}\text { Incidence }(95 \% \mathrm{Cl}) \text { per } 10000 \\
\text { person years at risk }\end{array}$ & $\begin{array}{c}10.0 \\
\text { (9.9 to } 10.1)\end{array}$ & $\begin{array}{c}10.4 \\
(10.1 \text { to } \\
10.6)\end{array}$ & $\begin{array}{c}10.3 \\
(10.1 \text { to } \\
10.5)\end{array}$ & $\begin{array}{c}9.9 \\
\text { (9.6 to } 10.1)\end{array}$ & $\begin{array}{c}9.2 \\
\text { (9.0 to } 9.5)\end{array}$ & $\begin{array}{c}10.1 \\
\text { (9.9 to } 10.4)\end{array}$ & $\begin{array}{c}7.8 \\
\text { (7.5 to } 8.0)\end{array}$ & $\begin{array}{l}9.5 \\
\text { (9.2 to } 9.7)\end{array}$ & $\begin{array}{c}9.9 \\
(9.7 \text { to } 10.2)\end{array}$ & $\begin{array}{c}10.6 \\
(10.3 \text { to } \\
10.9)\end{array}$ & $\begin{array}{c}12.0 \\
(11.7 \text { to } 12.3)\end{array}$ \\
\hline No of deaths of known cause: & 25360 & 4909 & 6055 & 5003 & 4643 & 4750 & 3538 & 4963 & 6109 & 4613 & 6137 \\
\hline Cardiovascular deaths & $12.5(3178)$ & $9.5(468)$ & 11.9 (719) & $12.6(631)$ & $11.9(553)$ & $17.0(807)$ & $8.3(293)$ & $10.9(543)$ & $11.8(720)$ & $13.0(600)$ & $16.7(1022)$ \\
\hline Non-cardiovascular deaths & $\begin{array}{c}87.5 \\
(22182)\end{array}$ & $90.5(4441)$ & $88.1(5336)$ & $87.4(4372)$ & $88.1(4090)$ & $83.0(3943)$ & $91.7(3245)$ & $89.1(4420)$ & $88.2(5389)$ & $87.0(4013)$ & 83.4 (5115) \\
\hline Cancer deaths & $14.3(3627)$ & $14.2(697)$ & 15.2 (918) & $14.1(706)$ & 13.7 (638) & $14.1(668)$ & $12.1(428)$ & $14.2(706)$ & $14.8(902)$ & $15.1(697)$ & $14.6(894)$ \\
\hline Suicide deaths & $28.7(7266)$ & $28.6(1406)$ & $28.4(1720)$ & $29.0(1450)$ & 30.1 (1396) & $27.2(1294)$ & 31.5 (1116) & $29.4(1458)$ & 28.4 (1733) & 28.1 (1295) & 27.1 (1664) \\
\hline $\begin{array}{l}\text { Deaths from other external } \\
\text { causes }\end{array}$ & $28.1(7123)$ & $31.0(1520)$ & $28.2(1706)$ & 27.5 (1376) & 28.4 (1318) & $25.3(1203)$ & $\begin{array}{l}35.0 \% \\
(1238)\end{array}$ & 29.7 (1472) & 28.0 (1708) & $27.0(1247)$ & 23.8 (1458) \\
\hline
\end{tabular}

Of 28934 men who had died by 31 December 2006, cause of death was known for all 25360 who died by 31 December 2004 .

Body mass index was defined as weight $(\mathrm{kg})$ in light clothing divided by height $(\mathrm{m})$ without shoes squared. Elbow flexion, hand grip, and knee extension strength were measured according to a standard protocol and used as indicators of lean body mass.

Using data from the Swedish population and housing censuses in 1960, 1970, 1980, and 1990, we classified household socioeconomic position as the highest of maternal and paternal socioeconomic position. If both were missing, we used the socioeconomic position of the military conscript.
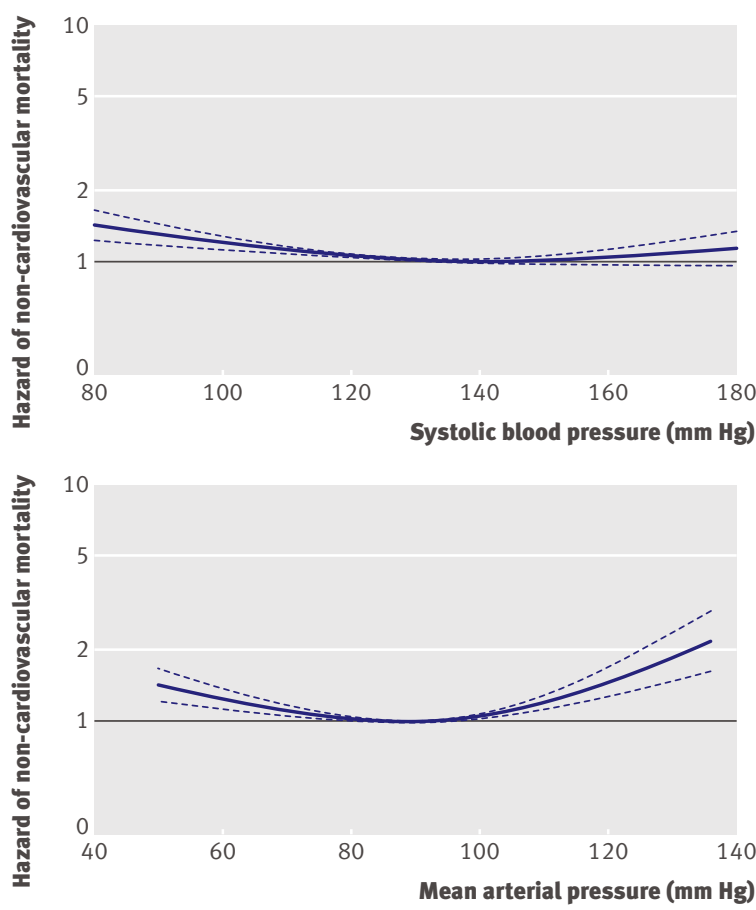

\section{Follow-up and outcome parameters}

Using the unique personal identification number assigned to each Swedish citizen, we linked the Military Conscription Registry to the Swedish Causes of Death Registry and Statistics Sweden's emigration registers, which both cover the entire Swedish population. In the main total mortality models, we considered participants to be at risk from the date of conscription and until the earliest of three possible events: death, date of emigration, or 31 December 2006. We followed participants for a maximum of 37 years (median 24, range
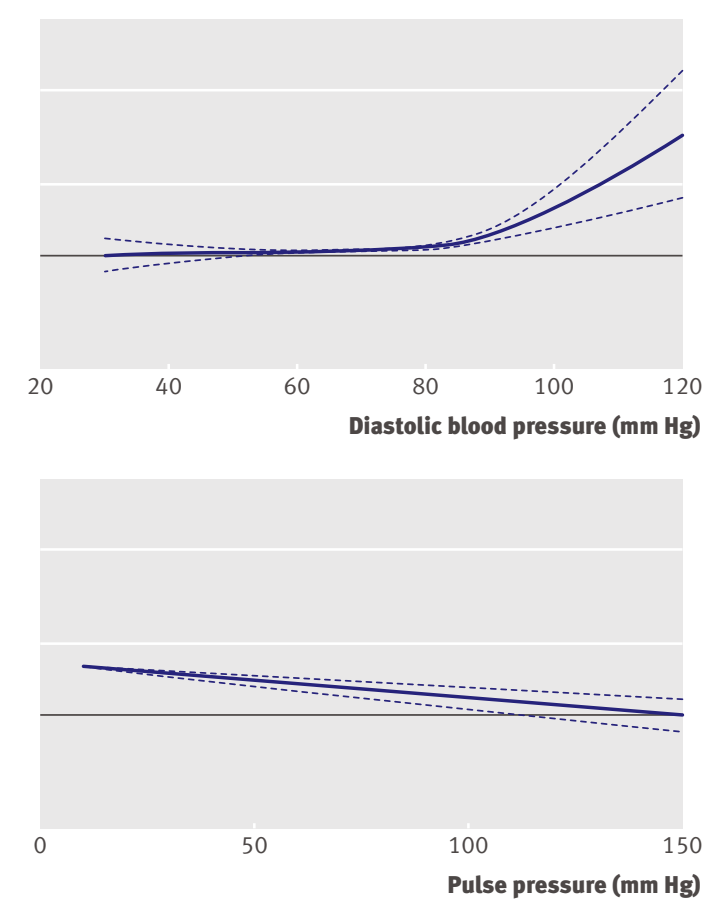

Fig 3 | Relations of systolic (top left), diastolic (top right), mean arterial (bottom left), and pulse (bottom right) pressures to non-cardiovascular mortality. Solid line represents hazard of non-cardiovascular mortality and dashed lines are $95 \%$ confidence interval limits, from multivariable regression spline Cox proportional hazards C models (adjusted for age, conscription date, conscription centre, socioeconomic position, body mass index, elbow flexion, hand grip, and knee extension strength). Y scale is logarithmic 

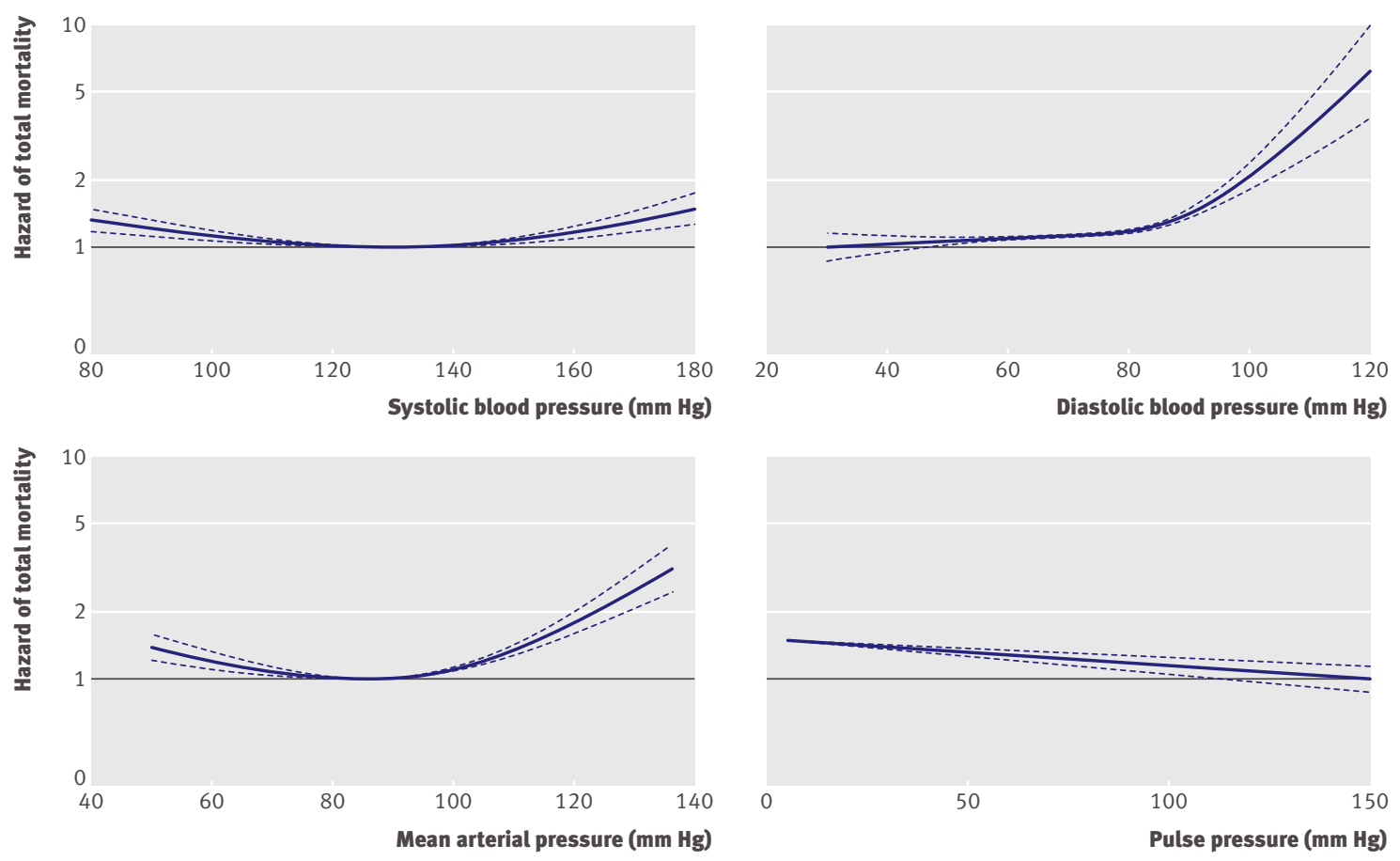

Fig 1| Relations of systolic (top left), diastolic (top right), mean arterial (bottom left), and pulse (bottom right) pressures to total risk of death. Solid line represents hazard of total mortality and dashed lines are $95 \%$ confidence interval limits, from multivariable regression spline Cox proportional hazards C models (adjusted for age, conscription date, conscription centre, socioeconomic position, body mass index, elbow flexion, hand grip, and knee extension strength). Y scale is logarithmic

0-37 years), which gave a total of 28998870 person years at risk. Apart from the 56202 (4.7\%) men who emigrated, no participants were lost to follow-up.

Causes of death up to the end of 2004 were known. In models investigating relations of blood pressures to risk of death from cardiovascular causes, noncardiovascular causes, cancer, suicide, and other external causes, we followed participants until 31 December 2004, during 26751397 person years at risk. Other causes of death were too few to be studied separately. Death from other external causes includes unintentional injuries such as traffic accidents, poisoning, falls, drowning, violence, and fire.

In secondary models run to assess possible reverse causation, we did not consider participants to be at risk until five years after the date of conscription. These models included 1197989 participants and 22982760 person years at risk.

\section{Statistical analysis}

Initially, we investigated distributional properties of all variables (web extra fig A). Thereafter, we used Cox proportional hazards models to investigate relations of blood pressures to risk of death. We initially sought to investigate the shape of those relations, and for that purpose we used multivariable regression spline models (a piecewise fitting of polynomial equations) with up to five degrees of freedom allowed for the blood pressure variables and one degree of freedom for continuous covariates. We placed knots at the fifth, 35th, 65 th, and 95th centiles. ${ }^{16}$ We present results of these models graphically and by showing systolic and diastolic pressures corresponding to specified levels $(10 \%, 25 \%, 50 \%$, and $100 \%)$ of higher predicted relative risk of death (compared with nadir of risk) from these models. We calculated population attributable fractions of mortality due to blood pressures above or below some of these blood pressure levels. Because quantile based results may be intuitive, we also analysed mortality by fifths of blood pressures. We chose fifths in an effort to balance maximum power with reasonable ability to model non-linear relations.

We accounted for age by using age as the timescale in all models. We considered three sets of covariates (models A, B, and C) for all spline and quintile models. The A models were age adjusted models. The $\mathrm{B}$ models were multivariable adjusted basic models, with adjustment for age, conscription date (to account for birth cohort effects), and conscription centre (to account for geographical catchment areas and systematic errors of the centres). The $\mathrm{C}$ models were multivariable adjusted mechanistic models similar to B models with the addition of socioeconomic position, body mass index, elbow flexion, hand grip, and knee extension strength (if blood pressures are on a substantial causal pathway between socioeconomic and lifestyle factors and mortality, adjustment for these factors will affect the blood pressure estimates). In secondary analyses, we investigated the common threshold levels of $140 \mathrm{~mm} \mathrm{Hg}$ systolic blood pressure and $90 \mathrm{~mm} \mathrm{Hg}$ diastolic blood pressure in models $\mathrm{A}$ to $\mathrm{C}$.

We assessed proportional hazards assumptions by inspecting Schoenfeld residuals in B models. We investigated multiplicative interaction terms between fifths 
Table 3 |Blood pressures (95\% confidence intervals) at specified levels of predicted mortality

\begin{tabular}{|c|c|c|c|}
\hline & Age adjusted A models* & Multivariable adjusted B models $†$ & Multivariable adjusted $\mathrm{C}$ models $\ddagger$ \\
\hline \multicolumn{4}{|c|}{ Systolic blood pressure } \\
\hline At lowest risk & 131 (125 to 139$)$ & 129 (123 to 137$)$ & 131 (124 to 139$)$ \\
\hline At $10 \%$ higher risk & 106 (98 to 110) and 153 (149 to 159) & 103 (93 to 108) and 152 (149 to 157) & $104(95$ to 109$)$ and $153(150$ to 160$)$ \\
\hline At $25 \%$ higher risk & 89 (- to 97$)$ and 165 (159 to 174$)$ & 86 (- to 94$)$ and 164 (159 to 173$)$ & 88 (- to 95$)$ and 166 (160 to 177$)$ \\
\hline At $50 \%$ higher risk & 178 (170 to -) & 177 (170 to -) & 180 (171 to -) \\
\hline \multicolumn{4}{|c|}{ Diastolic blood pressure } \\
\hline At lowest risk & $30(-$ to 39$)$ & $30(-$ to 46$)$ & 30 (- to 47$)$ \\
\hline At $10 \%$ higher risk & $40(-$ to 46$)$ & $57(-$ to 60$)$ & 62 (53 to 66) \\
\hline At $25 \%$ higher risk & 55 (52 to 57$)$ & $82(81$ to 84$)$ & 85 (83 to 86$)$ \\
\hline At $50 \%$ higher risk & $81(80$ to 83$)$ & $90(89$ to 91$)$ & 92 (91 to 94$)$ \\
\hline At $100 \%$ higher risk & 92 (91 to 94) & 97 (95 to 100) & 99 (97 to 104) \\
\hline
\end{tabular}

*Multivariable regression spline models adjusted for age.

†Adjusted for age, conscription date, and conscription centre.

$\ddagger$ Similar to B with additional adjustment for socioeconomic position, body mass index, elbow flexion, hand grip, and knee extension strength.

of blood pressure and body mass index, socioeconomic position, age, conscription date, and smoking in B models. For the purpose of illustrating any interactions, we present relations of fifths of systolic and diastolic blood pressures to mortality in subgroups of body mass index, socioeconomic index, age, and conscription date in $\mathrm{B}$ models in a figure.

Because data on smoking were available in only a small fraction of the sample $(\mathrm{n}=39526)$ with the longest follow-up (conscription years 1969-70), we did secondary analyses of $\mathrm{C}$ models with and without additional adjustment for smoking, censoring participants at the median follow-up of the total sample (to obtain a case mix similar to the total sample).

We give two tailed 95\% confidence intervals and $\mathrm{P}$ values. We used Stata 11 for all analyses.

\section{RESULTS}

Table 1 shows baseline characteristics of the sample. During follow-up, 28934 (2.4\%) participants died, giving an incidence of 10.0 (95\% confidence interval 9.9 to 10.1) per 10000 person years at risk (table 2).

Nature of relations of blood pressures to total mortality In multivariable regression spline models, the relation of systolic blood pressure to mortality was U shaped (fig 1, top left panel). The lowest mortality was at a systolic blood pressure of about $130 \mathrm{~mm} \mathrm{Hg}$; mortality was greater with both higher and lower blood pressures. The relation of diastolic blood pressure to risk of death was monotonic and positive. The relation was marginal in the lower part of the distribution of diastolic blood pressure, but a steeper increase in risk occurred at diastolic blood pressures above about $90 \mathrm{~mm} \mathrm{Hg}$ (fig 1, top right panel). The relation of mean arterial pressure to mortality was J shaped, and pulse pressure was inversely related to mortality (fig 1, bottom panels).

Table 3 shows systolic and diastolic blood pressures at specified levels of predicted risk of death from the multivariable regression spline models. If one considers a $50 \%$ higher risk to be clinically relevant, for example, such an elevated risk (compared with the risk nadir) occurred at a systolic blood pressure of about $180 \mathrm{~mm} \mathrm{Hg}$ and a diastolic blood pressure of about $90 \mathrm{~mm} \mathrm{Hg}$.

Population attributable fractions of mortality due to suboptimal blood pressures

We calculated population attributable fractions of mortality by using threshold levels of blood pressure corresponding to the specified risk levels from $\mathrm{C}$ models in table 3 . When we used blood pressure levels indicating 10\% higher risks, the population attributable fraction due to systolic blood pressures below $104 \mathrm{~mm} \mathrm{Hg}$ or above $153 \mathrm{~mm} \mathrm{Hg}$ corresponded to $0.4 \%$ and the population attributable fraction due to diastolic blood pressures above $62 \mathrm{~mm} \mathrm{Hg}$ was $20.1 \%$. The population attributable fraction of all deaths due to a combination of these blood pressure levels was also $20.1 \%$. Corresponding population attributable fractions for blood pressure thresholds indicating 25\% higher risks (systolic blood pressure below 88 or above $166 \mathrm{~mm} \mathrm{Hg}$; diastolic blood pressure above $85 \mathrm{~mm} \mathrm{Hg}$ ) were $0.1 \%, 1.9 \%$, and $1.9 \%$.

\section{Quintile models}

Mortality was similar in the lowest and highest fifths of systolic blood pressure, with a lower risk in between (table 4). The risk of death was lowest in the lowest fifth of diastolic blood pressure, with gradually higher risks in higher fifths (table 4). The spline models indicated a risk threshold at a diastolic blood pressure of about $90 \mathrm{~mm} \mathrm{Hg}$, which the quintile models were too crude to capture.

\section{Nature of relations of blood pressures to cause specific} mortality

During follow-up until 31 December 2004, 25360 $(2.1 \%)$ men died. Of these, $3178(12.5 \%)$ participants died of cardiovascular diseases, with an incidence of 1.2 (1.2 to 1.2$)$ per 10000 person years at risk, and $22182(87.5 \%)$ died of non-cardiovascular causes, giving an incidence of 8.3 (8.2 to 8.4) per 10000 person years at risk. Among the non-cardiovascular deaths, $7266(28.7 \%$ of all deaths) were due to suicide 

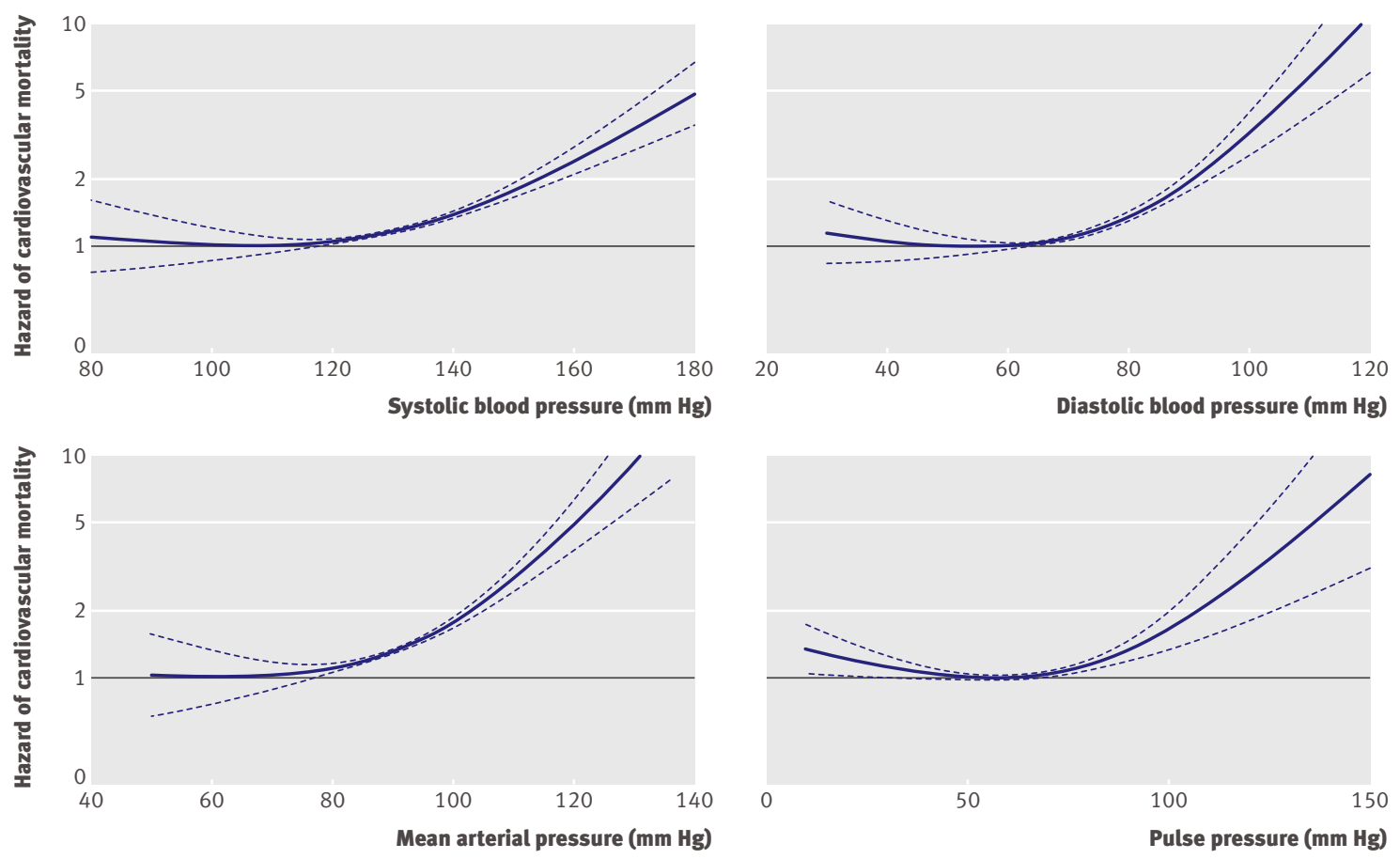

Fig 2 Relations of systolic (top left), diastolic (top right), mean arterial (bottom left), and pulse (bottom right) pressures to cardiovascular mortality. Solid line represents hazard of cardiovascular mortality and dashed lines are $95 \%$ confidence interval limits, from multivariable regression spline Cox proportional hazards C models (adjusted for age, conscription date, conscription centre, socioeconomic position, body mass index, elbow flexion, hand grip, and knee extension strength). Y scale is logarithmic

(incidence 2.7 (2.7 to 2.8 ) per 10000 person years), $3627(14.3 \%)$ were due to cancer (incidence $1.4(1.3$ to 1.4$)$ per 10000 person years), and $7123(28.1 \%)$ were due to other external causes (incidence 2.7 (2.6 to 2.7) per 10000 person years at risk).

In multivariable regression spline models, the relations of systolic, diastolic, mean arterial, and pulse pressures to cardiovascular mortality were mainly monotonic and positive (fig 2), with little or no relations seen in the lower parts of the distributions. The relations of systolic, diastolic, mean arterial, and pulse pressures to non-cardiovascular mortality (fig 3) were almost identical to their relations to total mortality. Subdividing the non-cardiovascular death causes further showed little or no relation of blood pressures to mortality due to cancer or suicide (figs 4 and 5); however, we found inverse relations of systolic, mean arterial, and pulse pressure to mortality from other external causes (fig 6).

\section{Secondary analyses}

We investigated threshold levels of blood pressure applicable in middle aged and older people. A systolic blood pressure at or above $140 \mathrm{~mm} \mathrm{Hg}$ compared with below $140 \mathrm{~mm} \mathrm{Hg}$ yielded a hazard ratio for total mortality of 1.02 (95\% confidence interval 0.99 to 1.05$)$ in model C. A diastolic blood pressure at or above $90 \mathrm{~mm}$ $\mathrm{Hg}$ compared with below $90 \mathrm{~mm} \mathrm{Hg}$ was more strongly related to total mortality, with a hazard ratio of 1.35 (1.26 to 1.45$)$ in model C. The population attributable fraction of all deaths due to systolic blood pressures above $140 \mathrm{~mm} \mathrm{Hg}$ corresponded to $0.4 \%$, that due to diastolic blood pressures above $90 \mathrm{~mm}$ $\mathrm{Hg}$ was also $0.4 \%$, and that due to a combination of these blood pressure levels was $0.5 \%$.

We investigated relations of combinations of systolic and diastolic blood pressures to total mortality (web extra fig B). Most of the relation of systolic blood pressure to mortality seemed to be driven by results in the stratum with diastolic blood pressure above the median. Similarly, most of the relation of diastolic blood pressure to mortality was driven by the relations in the stratum with systolic blood pressure above the median.

In secondary models starting follow-up five years after the date of conscription, 24911 (2.1\%) of 1197989 men died. Relations of systolic and diastolic blood pressures to mortality were similar to those in the primary sample (data not shown).

In the sample of 39526 men with available data on smoking, $829(2.1 \%)$ died during a median of 24.2 years of follow-up. Adjustment for smoking did not materially affect the relations, and confidence intervals were wide and could accommodate relations such as those in the total sample (data not shown).

We found no deviation from proportionality of hazards. Owing to the large sample size, some product terms with the highest fifths of blood pressure were statistically significant (systolic blood pressure*body mass index, systolic blood pressure*conscription date, and diastolic blood pressure*body mass index). 
Table $4 \mid$ Cox proportional hazard ratios ( $95 \%$ confidence intervals) for mortality, comparing fifths of blood pressures with lowestfifth

\begin{tabular}{lccc}
\hline & $\begin{array}{c}\text { Age adjusted } \\
\text { A models* }\end{array}$ & $\begin{array}{c}\text { Multivariable adjusted } \\
\text { B models } \dagger\end{array}$ & $\begin{array}{c}\text { Multivariable adjusted } \\
\text { C models }\end{array}$ \\
\begin{tabular}{l} 
Systolic blood pressure \\
\hline $80-119 \mathrm{~mm} \mathrm{Hg}$
\end{tabular} & 1 & 1 & 1 \\
\hline $120-125 \mathrm{~mm} \mathrm{Hg}$ & $0.96(0.93$ to 1.00$)$ & $0.96(0.92$ to 0.99$)$ & $0.95(0.92$ to 0.98$)$ \\
\hline $126-130 \mathrm{~mm} \mathrm{Hg}$ & $0.97(0.93$ to 1.00$)$ & $0.97(0.94$ to 1.01$)$ & $0.96(0.93$ to 1.00$)$ \\
\hline $131-138 \mathrm{~mm} \mathrm{Hg}$ & $0.94(0.91$ to 0.98$)$ & $0.96(0.92$ to 0.99$)$ & $0.95(0.91$ to 0.99$)$ \\
\hline $139-184 \mathrm{~mm} \mathrm{Hg}$ & $0.99(0.95$ to 1.03$)$ & $1.00(0.96$ to 1.04$)$ & $0.98(0.95$ to 1.02$)$ \\
\hline Diastolic blood pressure & & & 1 \\
\hline $30-59 \mathrm{~mm} \mathrm{Hg}$ & 1 & $1.02(0.98$ to 1.06$)$ & $1.01(0.97$ to 1.06$)$ \\
\hline $60-65 \mathrm{~mm} \mathrm{Hg}$ & $1.07(1.02$ to 1.11$)$ & $1.04(0.99$ to 1.08$)$ & $1.02(0.98$ to 1.07$)$ \\
\hline $66-70 \mathrm{~mm} \mathrm{Hg}$ & $1.09(1.05$ to 1.14$)$ & $1.08(1.04$ to 1.13$)$ & $1.06(1.02$ to 1.11$)$ \\
\hline $71-76 \mathrm{~mm} \mathrm{Hg}$ & $1.15(1.10$ to 1.20$)$ & $1.15(1.11$ to 1.20$)$ & $1.12(1.07$ to 1.17$)$ \\
\hline $77-120 \mathrm{~mm} \mathrm{Hg}$ & $1.24(1.20$ to 1.29$)$ &
\end{tabular}

*Multivariable regression spline models adjusted for age.

†Adjusted for age, conscription date, and conscription centre.

$\ddagger$ Similar to B with additional adjustment for socioeconomic position, body mass index, elbow flexion, hand grip, and knee extension strength.

Web extra figure $\mathrm{C}$ shows stratified quintile models. We found no interaction with smoking (all $\mathrm{P}>0.13$ ).

\section{DISCUSSION}

In this nationwide cohort study of more than 1.2 million young men with up to 37 years of follow-up, the relation of diastolic blood pressure to total mortality was stronger than that of systolic blood pressure, in terms of both magnitude of predicted risk and population attributable fraction of mortality. The relation of diastolic blood
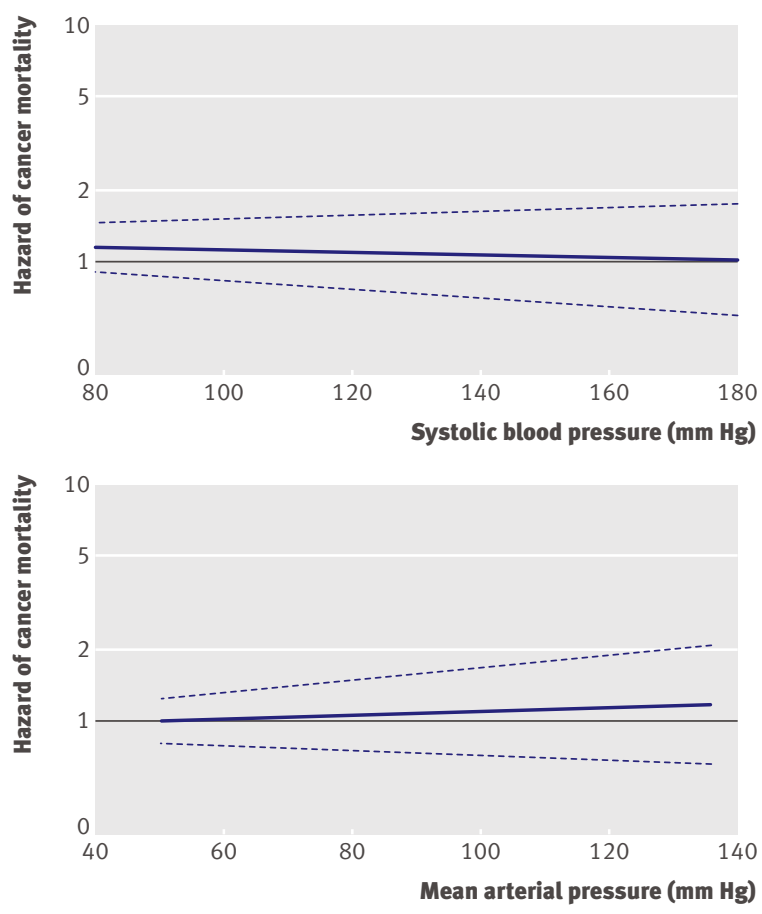

pressure to mortality was monotonic and positive, with an apparent risk threshold around a pressure of about $90 \mathrm{~mm} \mathrm{Hg}$. The relation of systolic blood pressure to mortality was U shaped, with the lowest risk at a pressure of about $130 \mathrm{~mm} \mathrm{Hg}$. The relations of both blood pressures to cardiovascular mortality were positive and monotonic, but their relations to non-cardiovascular mortality were similar to the relations to total mortality and were driven by inverse relations of systolic blood pressure to risk of death from external causes. The relations seen were not explained by measured covariates or reverse causality.

Association of blood pressure in late adolescence with cardiovascular mortality

Relations of systolic and diastolic blood pressures to risk of cardiovascular events have been reported in samples of college students and young industrial workers, ${ }^{9-11}$ as well as in the cohort studied here. ${ }^{12}$ The described relations are similar to those seen in samples of middle aged and older people and are congruent with the observations of our study.

Blood pressure levels in adolescence are strongly associated with blood pressure levels in later life, ${ }^{17}$ and high blood pressure in young people is explained by the same factors as in older adults-for example, obesity and physical inactivity. ${ }^{18}$ The pathways underlying the observed relations of high systolic and diastolic blood pressure in adolescence to subsequent cardiovascular mortality are most likely to be the same ones that are at work in adults, including left
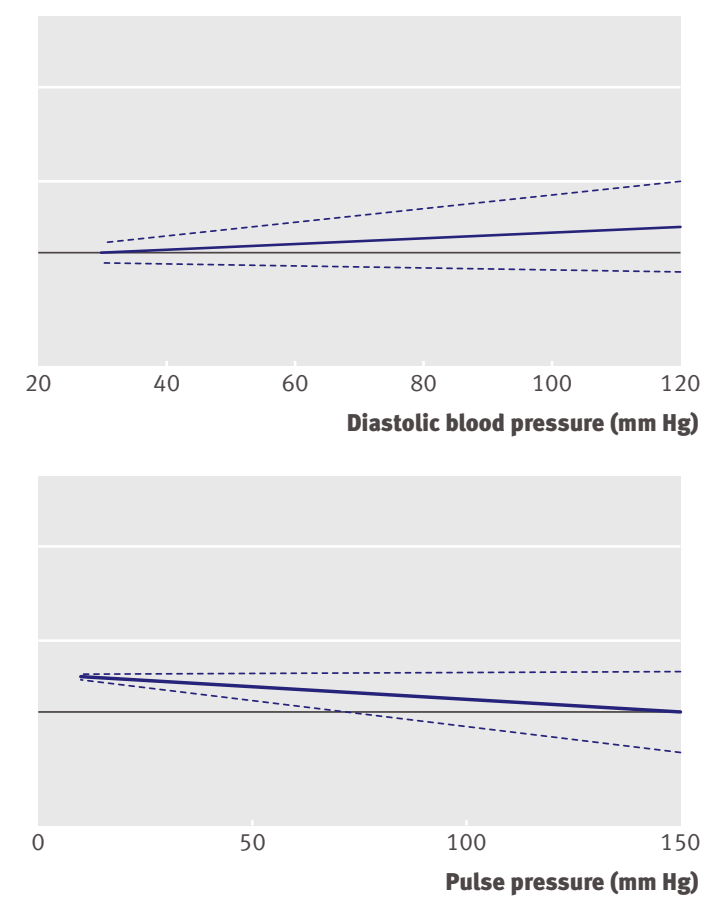

Fig 4| Relations of systolic (top left), diastolic (top right), mean arterial (bottom left), and pulse (bottom right) pressures to cancer mortality. Solid line represents hazard of non-cardiovascular mortality and dashed lines are $95 \%$ confidence interval limits, from multivariable regression spline Cox proportional hazards C models (adjusted for age, conscription date, conscription centre, socioeconomic position, body mass index, elbow flexion, hand grip, and knee extension strength). Y scale is logarithmic 

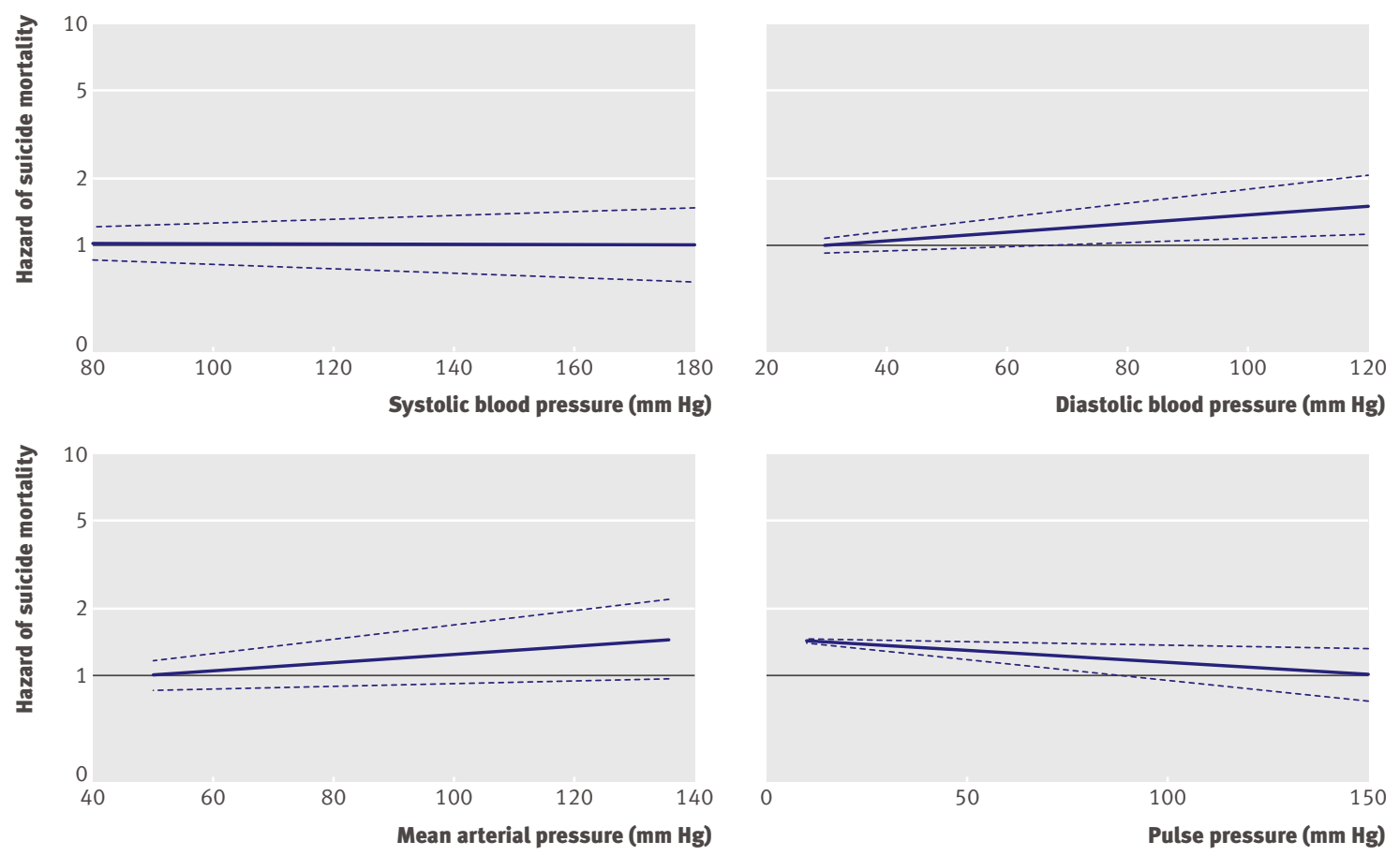

Fig 5 | Relations of systolic (top left), diastolic (top right), mean arterial (bottom left), and pulse (bottom right) pressures to risk of death from suicide. Solid line represents hazard of non-cardiovascular mortality and dashed lines are $95 \%$ confidence interval limits, from multivariable regression spline Cox proportional hazards C models (adjusted for age, conscription date, conscription centre, socioeconomic position, body mass index, elbow flexion, hand grip, and knee extension strength). Y scale is logarithmic

ventricular hypertrophy and coronary atherosclerosis, ${ }^{19-21}$ supported by the observation that blood pressures were positively related to cardiovascular mortality in our study.

Isolated diastolic hypertension is more common in obese people, ${ }^{22}$ and Swedish military conscripts have become increasingly obese during the past decades. ${ }^{23}$ Increases in blood pressure in US children and adolescents during these decades have been partly attributed to a simultaneous increase in the prevalence of overweight, ${ }^{24}$ but opposite relations reported from other repeated surveys illustrate the fact that the relations of blood pressure and trends in overweight need more research. ${ }^{25}$ We have accounted as far as possible for the influence of body composition on the observed relations by adjusting for body mass index and muscle strength and for temporal trends in body mass index by adjusting for date of conscription.

\section{Association of blood pressure in late adolescence with non-cardiovascular mortality}

Because cardiovascular disease is the underlying cause of a small minority of deaths in young and middle aged people ${ }^{26}$ investigating relations to total mortality and other causes of mortality in this age group is important. The mechanisms behind the $U$ shaped relations of systolic blood pressure to total mortality and non-cardiovascular mortality are intriguing.

Confounding by bodily constitution is possible. People with sustained hypotension differ from others in several respects, ${ }^{27}$ and a low body mass index is often described. In our study, the higher non-cardiovascular mortality seen in men with low systolic blood pressure was independent of body mass index and muscle strength, and the higher mortality was not confined to people with very low blood pressure but was graded and evident also in those with low-normal blood pressure.

Low habitual systolic blood pressure has been associated with poor social, physical, and mental wellbeing, ${ }^{28}$ as well as with a higher prevalence of anxiety and depression. ${ }^{29}$ The relations seen were not affected by adjustment for socioeconomic position, but residual confounding by social status or related factors is possible. Suicide is a major cause of death in young people, ${ }^{26}$ but the relation of low systolic blood pressure to non-cardiovascular mortality seen in our study was not explained to any major extent by death from suicide.

In some previous studies, ${ }^{3031}$ a U or J shaped relation of blood pressure to mortality has been observed during the first years of follow-up, with a linear relation seen over longer time periods. This is congruent with reverse causation - that is, that pre-existing illness explains both the low blood pressure and the impending death. The likelihood of reverse causation as a major explanation in this study is low because of the low prevalence of underlying disease at this age, because severe physical or mental handicap and chronic disease were legal reasons to be exempted from the conscription examinations, and because results were almost identical in analyses excluding the first five years of follow-up. Furthermore, death 

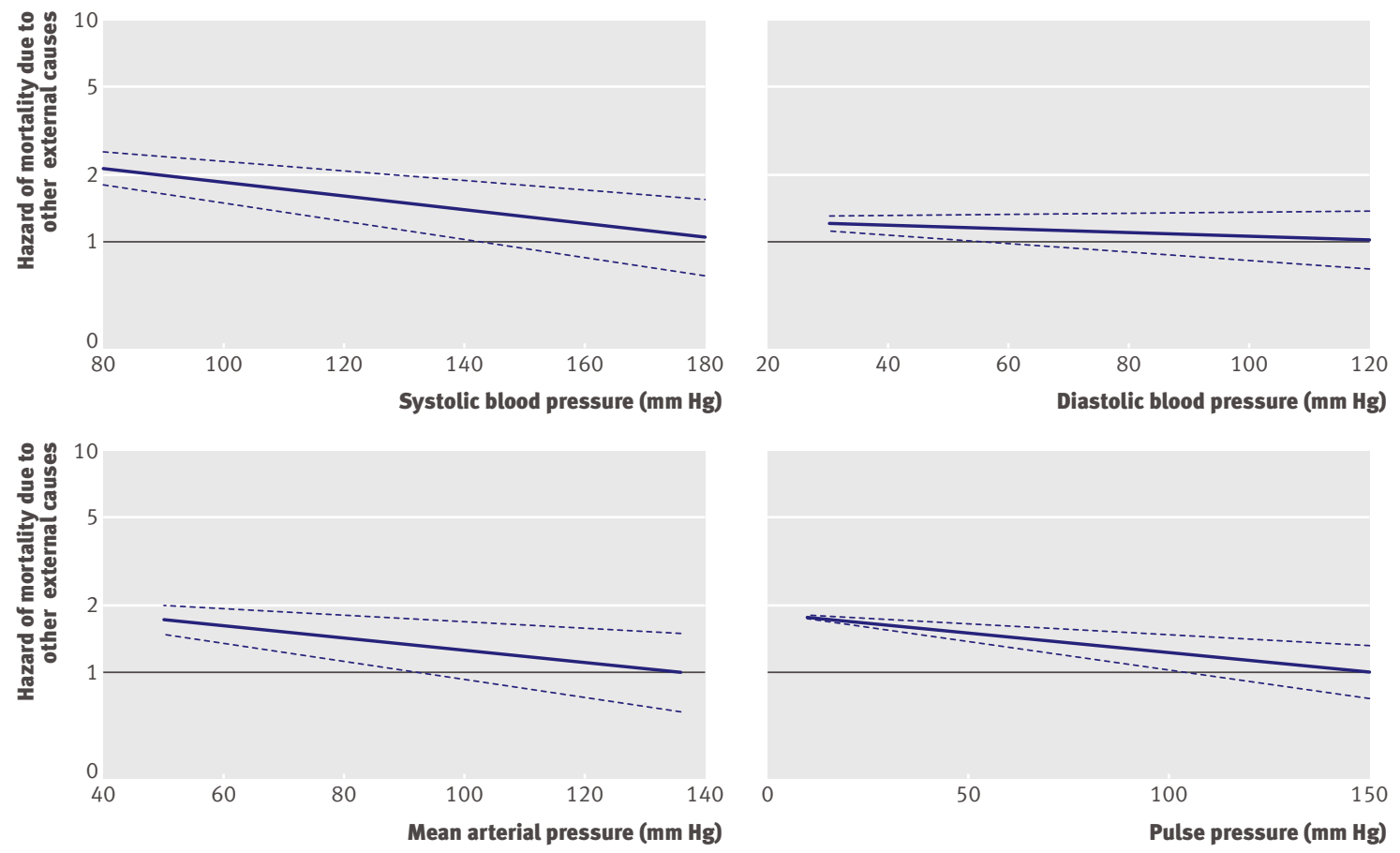

Fig 6 Relations of systolic (top left), diastolic (top right), mean arterial (bottom left), and pulse (bottom right) pressures to risk of death from other external causes. Solid line represents hazard of non-cardiovascular mortality and dashed lines are $95 \%$ confidence interval limits, from multivariable regression spline Cox proportional hazards C models (adjusted for age, conscription date, conscription centre, socioeconomic position, body mass index, elbow flexion, hand grip, and knee extension strength). $Y$ scale is logarithmic

from cancer was not a major explanation for the $\mathrm{U}$ shaped relation.

Possible causal mechanisms may also be considered. Constitutionally low blood pressure has been associated with diminished cognitive performance, mainly involving attention and reaction time. ${ }^{323}$ Impaired brain perfusion due to the low blood pressure or carotid baroreflex abnormalities explaining both low blood pressure and low cortical arousal have been implicated. $^{33}$ Accidents are an important cause of death in this age range. ${ }^{26}$ This pathway may be considered as a potential explanation for our observations, as lower systolic, mean arterial, and pulse pressures were associated with higher risk of death from external causes.

Another conceivable, but unlikely, causal mechanism is syncope. Constitutional hypotension is an infrequent cause of syncope ${ }^{34}$ but syncope associated with low blood pressure has an adverse prognosis. ${ }^{35}$ This pathway would also be congruent with the higher risk of death from external causes seen in our study.

The relation of diastolic blood pressure to noncardiovascular mortality cannot be explained by further subdividing the causes of death and so remains to be elucidated. Misclassified cardiovascular deaths or causes of death too infrequent to be studied separately may contribute to this relation.

\section{Strengths and limitations}

Limitations of the study include an unknown generalisability to women and ethnic groups other than white
European and the measurement of predictors on only one occasion. Men with higher blood pressures at baseline are more likely to have developed sustained, possibly treated, hypertension during follow-up; such information is lacking in this study. Some non-differential misclassification bias due to rounding of blood pressure values will, if anything, have slightly attenuated the associations. The procedure of re-measuring very high and very low blood pressures may have reduced the risk of chance findings. Residual or unmeasured confounding may exist. In particular, a very limited sample with information on smoking rendered the models adjusted for smoking imprecise. Even if the observed U shaped relations could partly be explained by confounding, they were robust across several analyses and represent important knowledge, as blood pressure and prevention guidelines do not differentiate between reasons for having a particular blood pressure.

The obvious advantage of the study is the very large sample size, which for the first time has enabled high precision analyses of relations of blood pressures to mortality in such a low risk sample. Variation in blood pressure due to exposure to environmental factors or pre-existing illness is probably low in this sample because of the low age. Furthermore, the participants were examined in a narrow age range, circumventing the considerable effects of ageing on blood pressure levels and mortality. Age was also accounted for by use of age as the timescale in the Cox models. Another strength was the use of splines. Several 


\section{WHAT IS ALREADY KNOWN ON THIS TOPIC}

High blood pressure is the most important risk factor for premature death globally, and blood pressure in adolescents is increasing

Because mortality is low in adolescents, previous studies have not been powered to investigate relations of systolic and diastolic blood pressures in adolescence to mortality

\section{WHAT THIS STUDY ADDS}

In 1207141 adolescent men, the relation of diastolic blood pressure to mortality risk was stronger than that of systolic blood pressure

The relation of diastolic blood pressure to mortality had a threshold at about $90 \mathrm{~mm} \mathrm{Hg}$, whereas the relation of systolic blood pressure to mortality was $U$ shaped, with a nadir at about $130 \mathrm{~mm} \mathrm{Hg}$
Contributors: JS conceived and designed the study, did all statistical analyses, analysed and interpreted the data, and drafted the article. PT, $\mathrm{MN}$, and FR contributed to acquisition and interpretation of the data and critical revision of the manuscript for important intellectual content. All researchers had access to all of the data in the study. JS is the guarantor. Funding: The study was funded by the Swedish Heart-Lung Foundation, the Swedish Research Council (grant 2007-5942), Uppsala University, and Arbetsmarknadens Forsakrings-och Aktiebolag. The funding sources had no role in the study design; in the collection, analysis, and interpretation of data; in the writing of the report; or in the decision to submit the paper for publication. Researchers were independent from the funders and sponsors of the study.

Competing interests: All authors have completed the Unified Competing Interest form at www.icmje.org/coi_disclosure.pdf (available on request from the corresponding author) and declare that (1) the authors have no support from any company for the submitted work; (2) the authors have no relationships with companies that might have an interest in the submitted work in the previous 3 years; (3) their spouses, partners, or children have no financial relationships that may be relevant to the submitted work; and (4) the authors have no non-financial interests that may be relevant to the submitted work.

Ethical approval: The Regional Ethics Committee at Karolinska Institutet, Stockholm, Sweden, approved the study.

Data sharing:E No additional data available.

1 Lopez AD, Mathers CD, Ezzati M, Jamison DT, Murray CJ. Global and regional burden of disease and risk factors, 2001: systematic analysis of population health data. Lancet 2006;367:1747-57.

2 Kearney PM, Whelton M, Reynolds K, Muntner P, Whelton PK, He J. Global burden of hypertension: analysis of worldwide data. Lancet 2005;365:217-23.

3 Franklin SS, Gustin W IV, Wong ND, Larson MG, Weber MA, Kannel WB, et al. Hemodynamic patterns of age-related changes in blood pressure: the Framingham Heart Study. Circulation 1997;96:308-15.

4 Lewington S, Clarke R, Qizilbash N, Peto R, Collins R. Age-specific relevance of usual blood pressure to vascular mortality: a metaanalysis of individual data for one million adults in 61 prospective studies. Lancet 2002;360:1903-13.

5 Williams B, Lindholm LH, Sever P. Systolic pressure is all that matters. Lancet 2008;371:2219-21.

6 Sagie A, Larson MG, Levy D. The natural history of borderline isolated systolic hypertension. N Engl J Med 1993;329:1912-7.

7 Franklin SS, Jacobs MJ, Wong ND, L'Italien GJ, Lapuerta P. Predominance of isolated systolic hypertension among middle-aged and elderly US hypertensives: analysis based on National Health and Nutrition Examination Survey (NHANES) III. Hypertension 2001;37:869-74.

8 Hayman LL, Meininger JC, Daniels SR, McCrindle BW, Helden L, Ross J, et al. Primary prevention of cardiovascular disease in nursing practice: focus on children and youth: a scientific statement from the American Heart Association Committee on Atherosclerosis, Hypertension, and Obesity in Youth of the Council on Cardiovascular Disease in the Young, Council on Cardiovascular Nursing, Council on Epidemiology and Prevention, and Council on Nutrition, Physical Activity, and Metabolism. Circulation 2007;116:344-57.

9 McCarron P, Smith GD, Okasha M, McEwen J. Blood pressure in young adulthood and mortality from cardiovascular disease. Lancet 2000;355:1430-1.

10 Paffenbarger RS Jr, Wing AL. Chronic disease in former college students: X. The effects of single and multiple characteristics on risk of fatal coronary heart disease. Am J Epidemiol 1969;90:527-35.

11 Miura K, Daviglus ML, Dyer AR, Liu K, Garside DB, Stamler J, et al. Relationship of blood pressure to 25-year mortality due to coronary heart disease, cardiovascular diseases, and all causes in young adult men: the Chicago Heart Association Detection Project in Industry. Arch Intern Med 2001;161:1501-8.

12 Silventoinen K, Magnusson PK, Neovius M, Sundstrom J, Batty GD, Tynelius $P$, et al. Does obesity modify the effect of blood pressure on the risk of cardiovascular disease? A population-based cohort study of more than one million Swedish men. Circulation 2008;118:1637-42.

13 European Society of Cardiology, European Heart Network, European Commission, World Health Organization. The European heart health charter. European Society of Cardiology, 2007.

14 Din-Dzietham R, Liu Y, Bielo MV, Shamsa F. High blood pressure trends in children and adolescents in national surveys, 1963 to 2002. Circulation 2007;116:1488-96.

15 Andreasson S, Allebeck P, Romelsjo A. Alcohol and mortality among young men: longitudinal study of Swedish conscripts. BMJ 1988;296:1021-5. tance of developing strategies for early risk detection and preventive efforts at young ages, ${ }^{81}$ these observations may have important public health implications. 
16 Harrell FE Jr. Regression modeling strategies: with applications to linear models, logistic regression, and survival analysis. Springer Science+Business Media, 2001

17 Chen X, Wang Y. Tracking of blood pressure from childhood to adulthood: a systematic review and meta-regression analysis. Circulation 2008;117:3171-80.

18 Dasgupta K, O’Loughlin J, Chen S, Karp I, Paradis G, Tremblay J, et al. Emergence of sex differences in prevalence of high systolic blood pressure: analysis of a longitudinal adolescent cohort. Circulation 2006;114:2663-70.

19 Hanevold C, Waller J, Daniels S, Portman R, Sorof J. The effects of obesity, gender, and ethnic group on left ventricular hypertrophy and geometry in hypertensive children: a collaborative study of the International Pediatric Hypertension Association. Pediatrics 2004;113:328-33.

20 Daniels SD, Meyer RA, Loggie JM. Determinants of cardiac involvement in children and adolescents with essential hypertension. Circulation 1990;82:1243-8.

21 Mahoney LT, Burns TL, Stanford W, Thompson BH, Witt JD, Rost CA, et al. Coronary risk factors measured in childhood and young adult life are associated with coronary artery calcification in young adults: the Muscatine Study. J Am Coll Cardiol 1996;27:277-84.

22 Chirinos JA, Franklin SS, Townsend RR, Raij L. Body mass index and hypertension hemodynamic subtypes in the adult US population. Arch Intern Med 2009;169:580-6.

23 Neovius M, Teixeira-Pinto A, Rasmussen F. Shift in the composition of obesity in young adult men in Sweden over a third of a century. Int J Obes (Lond) 2008;32:832-6.

24 Muntner P, He J, Cutler JA, Wildman RP, Whelton PK. Trends in blood pressure among children and adolescents. JAMA 2004;291:2107-13.

25 Watkins D, McCarron P, Murray L, Cran G, Boreham C, Robson P, et al. Trends in blood pressure over 10 years in adolescents: analyses of cross sectional surveys in the Northern Ireland Young Hearts project. BMJ 2004:329:139.

26 Batty GD, Wennerstad KM, Smith GD, Gunnell D, Deary IJ, Tynelius P, et al. IQ in early adulthood and mortality by middle age: cohort study of 1 million Swedish men. Epidemiology 2009;20:100-9.

27 Akahoshi M, Hida A, Imaizumi M, Soda M, Maeda R, Ichimaru S, et al. Basic characteristics of chronic hypotension cases: a longitudinal follow-up study from 1958 through 1999. Hypertens Res 2006;29:1-7.
28 Rosengren A, Tibblin G, Wilhelmsen L. Low systolic blood pressure and self perceived wellbeing in middle aged men. $B M$ J 1993;306:243-6

29 Hildrum BR, Mykletun A, Stordal E, Bjelland I, Dahl AA, Holmen J. Association of low blood pressure with anxiety and depression: the Nord-Tröndelag Health Study. J Epidemiol Community Health 2007;61:53-8.

30 Flack JM, Neaton J, Grimm R Jr, Shih J, Cutler J, Ensrud K, et al. Blood pressure and mortality among men with prior myocardial infarction. Circulation 1995;92:2437-45.

31 Glynn RJ, Field TS, Hebert PR, Taylor JO, Hennekens CH, Rosner B, et al. Evidence for a positive linear relation between blood pressure and mortality in elderly people. Lancet 1995;345:825-9.

32 Wharton W, Hirshman E, Merritt P, Stangl B, Scanlin K, Krieger L. Lower blood pressure correlates with poorer performance on visuospatial attention tasks in younger individuals. Biol Psychol 2006;73:227-34.

33 Duschek S, Schandry R. Reduced brain perfusion and cognitive performance due to constitutional hypotension. Clin Auton Res 2007;17:69-76

34 Mathias CJ, Deguchi K, Schatz I. Observations on recurrent syncope and presyncope in 641 patients. Lancet 2001;357:348-53.

35 Quinn JV, Stiell IG, McDermott DA, Sellers KL, Kohn MA, Wells GA Derivation of the San Francisco syncope rule to predict patients with short-term serious outcomes. Ann Emerg Med 2004;43:224-32.

36 National High Blood Pressure Education Program Working Group on High Blood Pressure in Children and Adolescents. The fourth report on the diagnosis, evaluation, and treatment of high blood pressure in children and adolescents. Pediatrics 2004;114:555-76.

37 Messerli FH, Mancia G, Conti CR, Hewkin AC, Kupfer S, Champion A et al. Dogma disputed: can aggressively lowering blood pressure in hypertensive patients with coronary artery disease be dangerous? Ann Intern Med 2006;144:884-93.

38 Boutitie F, Gueyffier F, Pocock S, Fagard R, Boissel JP, for the INDANA Project Steering Committee. J-shaped relationship between blood pressure and mortality in hypertensive patients: new insights from a meta-analysis of individual-patient data. Ann Intern Med 2002;136:438-48.

Accepted: 09 December 2010 